\title{
Assessment of Water Harvesting System for a Smart Building Considering Climate Change
}

\author{
M. Abdellatif, A. Al-Shamma'a, S. Tunnington, R. Al khaddar, and W. Atherton
}

\begin{abstract}
With climate change now a reality rather than speculated possibility, the future change of rainfall pattern will affect the demand for potable water. Forth coming regulatory changes will mean that over $90 \%$ of UK homes will have their water usage metered, making consumers more and more aware of how expensive the commodity of "common or garden" water has become. In this paper the design of different rainwater harvesting systems (RWH) is evaluated for three residential properties of different roof areas. The design considered climate change effect and change in future rainfall for three periods 2020s, 2050s and 2080s under the high (AIFI) and low (B1) SRES scenarios in NW of England. The RWH systems were shown to fulfill between $25 \%$ and $85 \%$ of WC, washing machine and outdoor use demand making the system more valuable as a sustainable solution.
\end{abstract}

Index Terms -Climate change, rainwater harvesting, rainfall, sustainability.

\section{INTRODUCTION}

Surcharging of stormwater drains is a problem that is exacerbated by intense rainfall and increasing development. Existing stormwater sewers become overloaded and surcharged, causing localised flooding incidents. If the stormwater discharges to a combined sewer then surcharging causes foul water to flood, which would have health implications as well as the potential to cause damage to property [1]. RWH can reduce flood risk in UK (especially summer storms), save energy/carbon emission (at least that associated with the displaced water) and save householders money.

RWH is now explicitly mentioned in UK key government documents such as the Building Research Establishment's Environmental Assessment Method [2] and the Code for Sustainable Homes [3]. A rating against the latter became mandatory for all new dwellings in May 2008, although developments only need to meet the minimum standard. Additionally, Future Water [4], the government's water strategy document and water company Strategic Direction Statements [5], identify that RWH has a part to play in urban water management strategies. Furthermore, the Draft Flood and Water Management Bill [6] promotes the use of sustainable drainage, defining such structures as 'any feature or aspect of a design that is designed to receive or facilitating the receipt of rainwater. $55 \%$ of treated water is used in

Manuscript received August 5, 2014; revised October 17, 2014.

The authors are with Liverpool John Moores University, United Kingdom (e-mail: m.e.abdellatif@ljmu.ac.uk, a.al-Shamma'a@1jmu.ac.uk@ljmu.ac.uk, sue@raincatcher.co.uk, w.atherton@ljmu.ac.uk). households and the UK Government, under their Sustainable Building Strategy, suggests that a $25 \%$ reduction in potable water use in new buildings is necessary. This $25 \%$ reduction can be partly met by efficient appliances, but the remainder will need to be met by other means. Rainwater harvesting is seen as the most likely option [1].

A number of factors have so far contributed to the lack of progress in RWH. Ambiguity in the financial viability of RWH systems is a key reason; lack of experience and the absence of well-run demonstration sites is another [7]. Nevertheless, there has been a rise in the number of RWH systems being implemented in residential properties, new commercial buildings and in schools.

There are some studies considered the RWH with mathematical modelling for purpose of design/performance assessment eg. [7]-[10]. However none of these considered the issue of climate change along with the water harvesting tank size.

The focus of this paper is mainly on RWH systems under climate change. So, long-term scenarios are therefore required to gain further knowledge of system behavior in order to develop robust and sustainable management for the buildings. Assessment for climate change is normally carried out by comparing future rainfall with baseline period (1961-1990) as recommended by Intergovernmental Panel on climate change (IPCC), so on average of 30 years time scale. This paper consider three future periods, the $2020 \mathrm{~s}$ (2010-2039), the 2050s (2040-2069) and the 2080s (2070-2099).

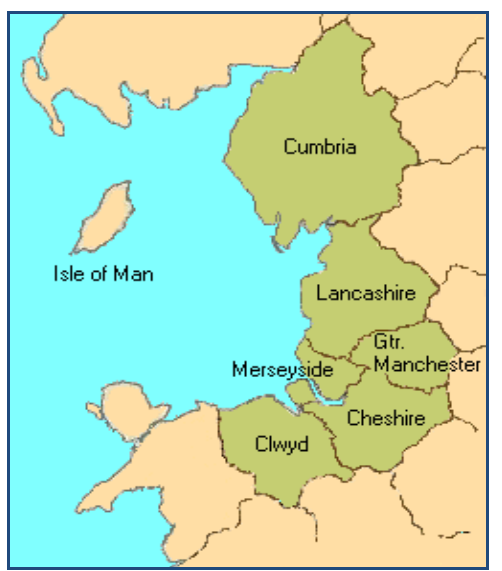

Fig. 1. Location of the studied sites (cumbria, lancashire \&cheshire).

\section{Sites Characteristics}

This study selected three residential properties at Cumbria, Lancashire \&Cheshire counties, represented by TW, WN and WR respectively in the North West of England (NW). The 
sites represent various climatic regions (the north, middle, and the south), as shown in Fig. 1. The exposure of the NW region to westerly maritime air masses and the presence of extensive areas of high ground mean that the region is considered as one of the wettest places in the UK. The average annual rainfall in the highest parts of the Cumbria is over $3200 \mathrm{~mm}$, in contrast to Manchester where the average annual rainfall is only $860 \mathrm{~mm}$ [11]. Table I show characteristics of the sample properties considered in each site.

TABLE I: DESIGN PARAMETERS AND VALUES FOR THE STUDIED SITES
\begin{tabular}{|l|c|c|c|}
\hline Parameter & Property 1 & Property 2 & Property 3 \\
\hline Roof area $\left(\mathrm{m}^{2}\right)$ & 60 & 100 & 150 \\
\hline No. of occupants & 3 & 4 & 6 \\
\hline No. rooms & 2 & 3 & 4 \\
\hline Analysis period (years) & 30 & 30 & 30 \\
\hline
\end{tabular}

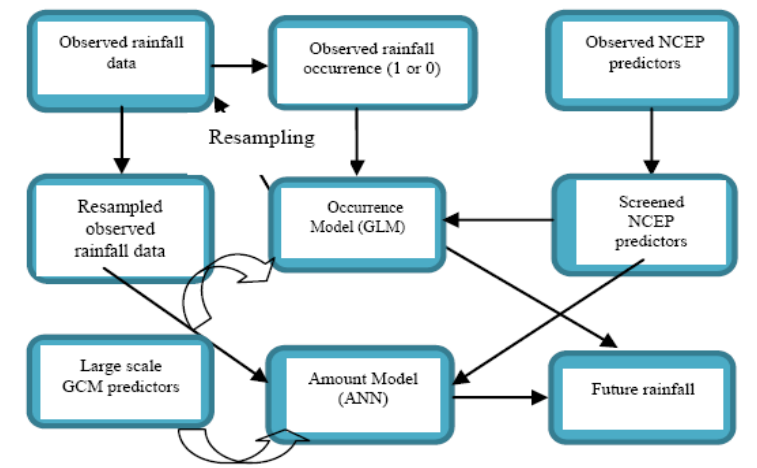

Fig. 2. A flow chart illustrating the downscaling procedure with hybrid GLM-ANN.

\section{Methodology}

\section{A. Future Rainfall}

Time series of rainfall are generally required as input to impacts models when assessing potential impacts arising as a consequence of global climate change. In order to produce plausible scenarios of change, it is of considerable importance that realistic series of rainfall, which reflect the large-scale changes in the atmosphere, are employed.

Future rainfall has been projected at the three locations in a previous study see [12] using a combination of Generalized Linear Model (GLM) and Artificial Neural Network ANN (hereinafter known as the hybrid GLM-ANN model, Fig. 2). Unlike other downscaling techniques, the developed model uses two-stage process to model rainfall; an occurrence process which uses the GLM with a logistic regression model and an amount process which uses an ANN network model trained with Levenberg-Marquardt approach. The developed model was used to simulate future rainfall using climatic variable produced from HadCM3 GCM for emissions scenarios high (A1FI) and low (B1) scenarios to understand relationship between climate change and hydrology in the selected sites, see [12] for calibration, verification of this model. The following is the description of the occurrence model (GLM),

$$
p_{i}\left(y_{i}\right)=\frac{1}{\left(1+e^{-\left(x_{i} \beta_{i}\right)}\right)}
$$

where,

$y_{i}=$ response which represent the $i$ th elements of the response vector $Y$.

$\beta_{i}=(k+1)$ column vector of unknown parameters to be estimated including the intercept.

$x_{i}=(k+1)$ raw vector of explanatory variables (climate predictors) accounting for the $i t h$ observation $(i=1 \ldots N)$.

$k=$ Number of predictors.

A multi-layer feed forward artificial neural network (MLF-ANN) model was used to build a non-linear relation between the observed rainfall amount series and the same selected set of climatic variables (predictors) used for the rainfall occurrence model [12].

\section{B. Rainwater Harvesting Tank Sizing}

Based on the British Standard BS 8515, the rainwater tank must be big enough to hold 5\% of the annual rainwater yield, or $5 \%$ of the annual non-potable water demand, whichever is the lesser and can be estimated as follows:

\section{1) Water yield}

Rainfall varies widely across the UK. Even sites quite close to each other can have quite different rainfall figures. The following equation gives the annual yield for water harvesting tank which is function of the annual rainfall depth.

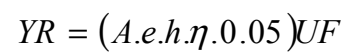

where:

$Y R=$ annual rainwater yield (5\% of) to give tank size (liters)

$A=$ collecting area $\left(\mathrm{m}^{2}\right)$

$e=$ yield coefficient -0.75 for tiled pitch roof

$h=$ annual depth of rainfall (mm)

$\eta=$ hydraulic filter efficiency- $90 \%$ minimum

$U F=$ assumed utilization factor- 0.75

The Baseline and future annual rainfall depths have been applied for water harvesting model yields for the three periods and the three sites under the high and low scenarios.

\section{2) Water usage (demand)}

Demand is dependent on the efficiency of appliances specified and purposes the rainwater will be used for. Demand is also dependent on the number of people and of days in the year the building is occupied and can be estimated as follows,

where:

$$
D N=P d . n .365 .0 .05
$$

$D N=$ annual non-potable rainwater demand $(5 \%$ of $)$ to give tank size (liters)

$P d=$ daily non-potable requirements per person (liter)

Domestic daily WC demand is $33 \%$ of daily water use per person which is 150 .

Domestic daily Outdoor demand is $3 \%$ of daily water use per person (150).

Domestic daily washing machine demand is $12 \%$ of daily water use per person (150).

$n=$ number of occupants

Tank saving efficiency can also be calculated using the equation:

$Y R / D N$ 


\section{RESUlTS AND DisCUSSION}

In order to verify whether the downscale rainfall model has the ability to capture the observed feature of each site an example of the verification has been presented below for both occurrence and amount (more details see [12]).

Monthly average wet days are indications of how often it rains in a month; it can be used as indirect measure of rainfall frequency. The visual plots in Fig. 3 show the monthly average wet days as well as dry days for the observed and simulated rainfall for the three sites for calibration and validation periods. All plots show that the occurrence model is well simulated by the GLM for all sites and periods which demonstrates that GLM is a good choice for downscaling future rainfall occurrence. This would entail the assumption that model parameters are assumed time invariant and would not change in future.
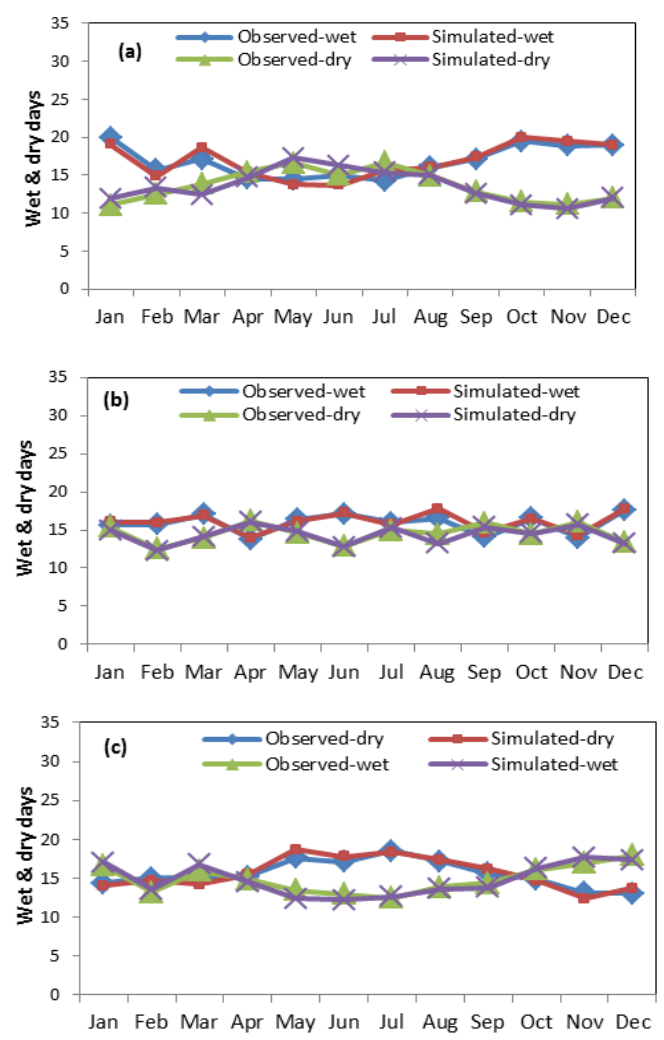

Fig. 3. Average numbers of wet and dry days for observed and simulated occurrence model for the (a) Cambria (b) Lancashire and (C) Cheshire.
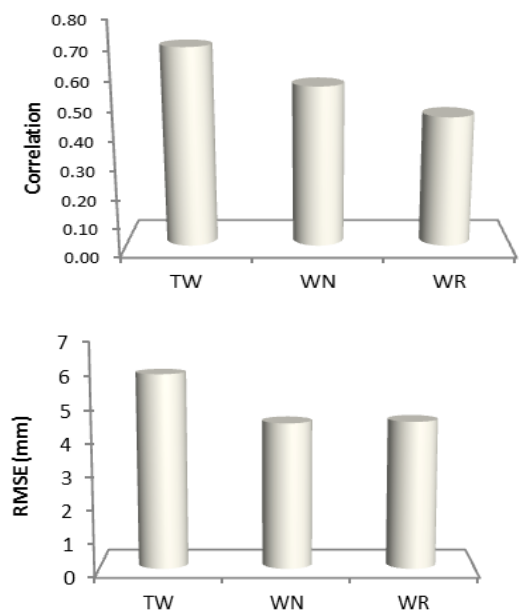

Fig. 4. Correlation (R) root mean square error (RMSE) of rainfall amount model.
The efficiency and ability of the rainfall model to predict rainfall amount that best matched the observed rainfall are expressed here in terms of their correlation coefficient (R) and root mean square error (RMSE) and presented in and Fig. 4 for the overall period 1961-2001. The higher values of R and lower values of RMSE obtained by models built using the hybrid GLM-ANN approach indicate that this modelling approach has reasonable accuracy in reproduce the rainfall amount.

Trend study for observed rainfall data is widely used as a base reference or a caveat of climate change studies e.g. [13].

It can also provide a quick visual check for the presence of unreasonable values (outliers). However, the usefulness of trend study is always being questioned. Possible trends in the data are investigated to offer an historical context before further climate change assessments in this work.

Fig. 5 shows the series plots and their trend lines for the average monthly rainfall for each station. Annual monthly rainfall series has no significance trend for all stations, based on the Wald test [14]. So generally, the plots indicate that climate change did not take place during the observed period data (1961-2001) for these locations, due to inclusion of the control period 1961-1990 in the trend study where the climate consider normal as reported by the IPCC.

Another analysis for the observed rainfall is the Inter-stations relationship. The daily rainfall box plots are different across the sites for the entire statistics, especially the 3rd percentile; median and maximum (see Fig. 6). In these Figures, the effects of threshold on rainfall distributions are also investigated for three sites. Selecting threshold is important because it is related to the definition of the occurrence of a rainfall event, the limitations inherent to the measurement of rainfall and the recording equipment.
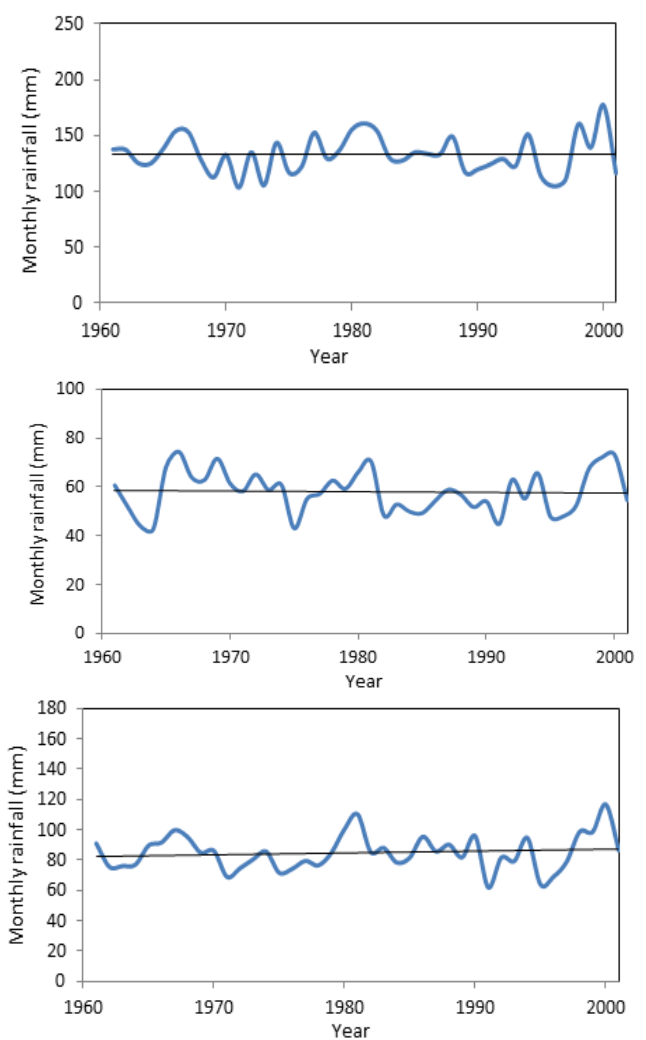

Fig. 5. The average monthly rainfall series with linear trend lines annual at Cumbria, Lancashire \&Cheshire (top to bottom). 

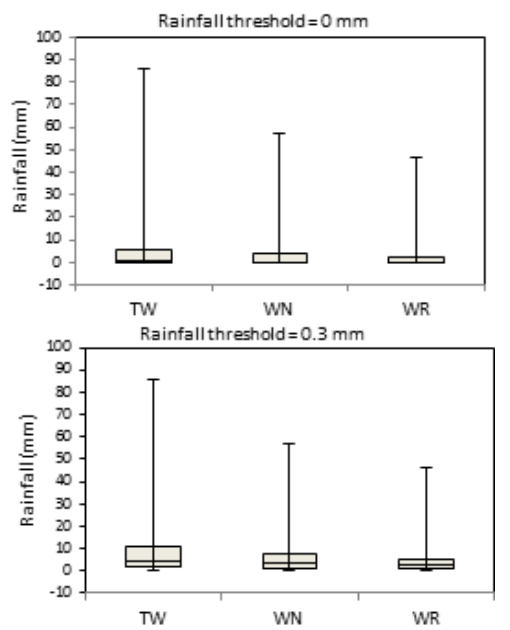

Fig. 6. The daily rainfall box plots across Cumbria (TW), Lancashire (WN) \&Cheshire (WR) for annual time series for 1961-2001.

Projection of future rainfall has been assessed. In Fig. 7 the small vertical error bars displayed at each point show the maximum and minimum of the annual average rainfall amount values of 30 years for 2020s, 2050s and 2080s. The annual rainfall, the maximum and minimum average rainfall can slightly increase or decrease for the three future periods at all sites.
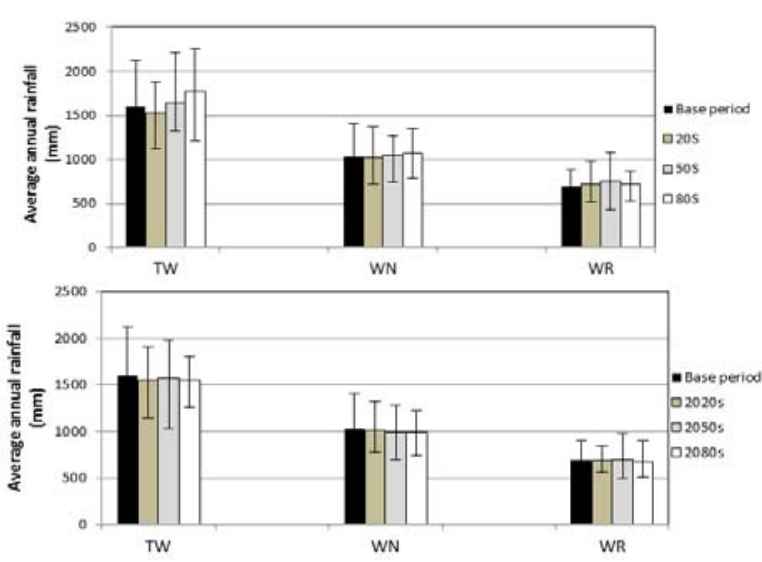

Fig. 7. Average annual rainfalls at the three sites in the future for A1FI (upper) and B1 (lower). The error bar indicates the minimum and maximum rainfall.

Impact of the projected future rainfall on RWH has been assessed. Results in Fig. 8 reveals that future annual yield for RWH at the three properties in Cumbria are projected to experience significant increase for tested high scenario (A1FI), especially in 2080 s where the yield could reach up to $11 \%$ as a maximum. However in the Lancashire (WN) and Cheshire (WR) results have showed a very slight rise, which is attributed to the location of Cumbria being in the wettest region in North-western England compared to others. The increase in annual yield significantly affects the amount of water supply saving with the same ratio for WC, outdoor and washing machine, with larger amount for property 2 and 3 due to larger roof area. The corresponding potable water saving at all sites will go up ranging between $27 \%-85 \%$ with largest amount associated with the 2080s compared with $26 \%-77 \%$ of the base period. For the low scenario the picture is somehow different where (Fig. 9) it is anticipated some decline in the annual yield and saving of RWH. The yield reduction could reach up to $3 \%$ at the three studied sites and for different properties sizes as they are suffer from a

reduction in the rainfall; however there is still significant annual future saving between $25 \%-75 \%$ compared with $27 \%-77 \%$ of the base period.
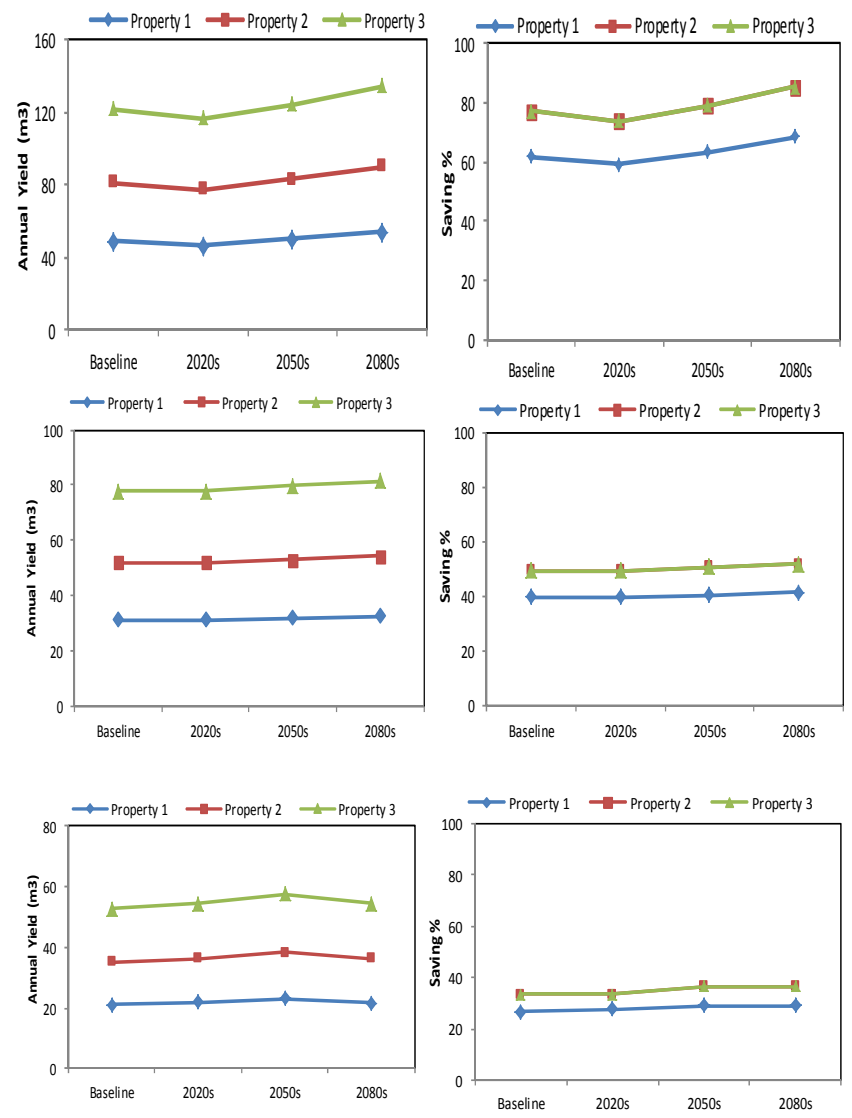

Fig. 8. Annual water yield and saving for water harvesting tank for the three future periods compared with baseline period under the high (A1FI) scenario for Cambria (upper), Lancashire (middle) and cheshire (lower).
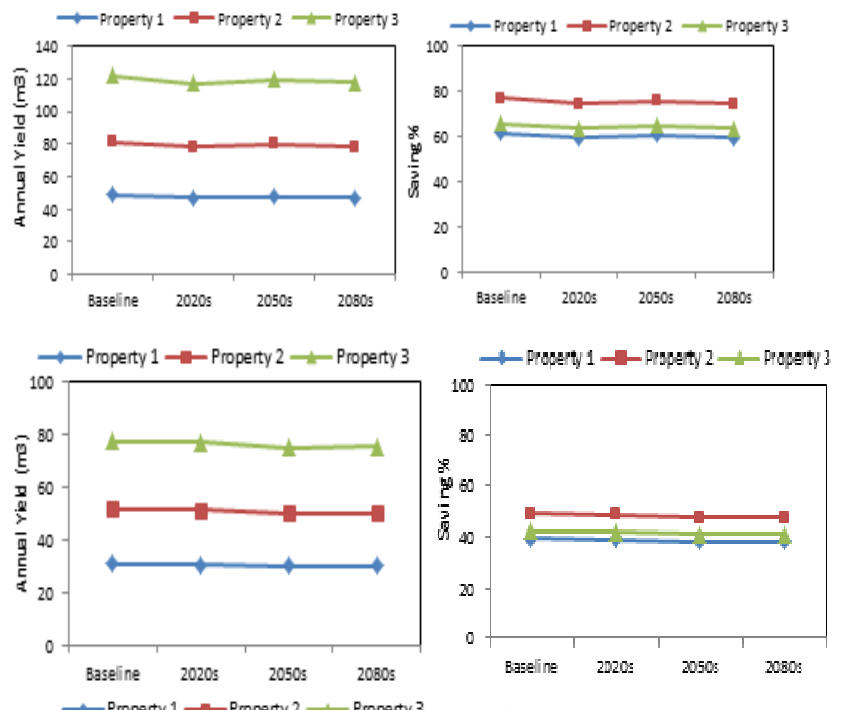

$\rightarrow$ Property $1 \rightarrow$-Property $2 \rightarrow$ Property 3

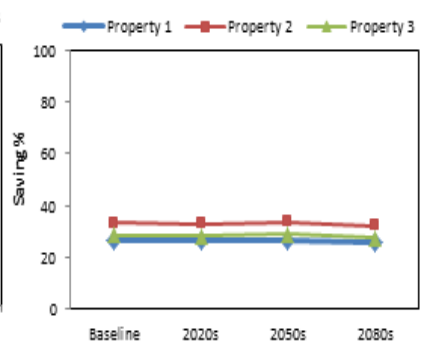

g. 9. Annual water yield and saving a for WHR tank for the three future periods compared with baseline period under the low (B1) scenario for Cambria (upper), Lancashire (middle) and Cheshire (lower) 
Impact on the RWH tank size is also investigated and results have been given in Table II, Table III and Table IV for Cambria, Lancashire and Cheshire. From the Tables, it is clear that the tank design is expected to change gradually in far future under A1FI scenario however the low scenario one experience consistent drops except in 2050s for Cheshire with very marginal contributions of $1 \%$. This could be due to the warm climate in this region which contribute to high evaporation and intern much rainfall. The increase in A1FI would range between $2 \%-11 \%$ with large contribution from Cambria.

TABLE II: PROPOSED FUtURE RWH TANK SiZE (LITRES) IN CAMBRIA (BOLD INDICATES AN INCREASE IN TANK SIZE)

\begin{tabular}{|l|l|l|l|l|l|l|}
\hline $\begin{array}{l}\text { Time } \\
\text { period }\end{array}$ & \multicolumn{2}{|c|}{ Property 1 } & \multicolumn{2}{|c|}{ Property 2 } & \multicolumn{2}{|l|}{ Property 3 } \\
\hline & A1FI & B1 & A1FI & B1 & A1FI & B1 \\
\hline $\begin{array}{l}\text { Base } \\
\text { period }\end{array}$ & 2433.0 & 2433.4 & 4055.1 & 4055.7 & 6082.6 & 6083.5 \\
\hline $2020 \mathrm{~s}$ & 2327.3 & 2348.1 & 3878.8 & 3913.6 & 5818.2 & 5870.3 \\
\hline $2050 \mathrm{~s}$ & $\mathbf{2 4 9 0 . 7}$ & 2391.4 & $\mathbf{4 1 5 1 . 2}$ & 3985.7 & $\mathbf{6 2 2 6 . 8}$ & 5978.5 \\
\hline $2080 \mathrm{~s}$ & $\mathbf{2 6 9 4 . 1}$ & 2353.1 & $\mathbf{4 4 9 0 . 2}$ & 3921.9 & $\mathbf{6 7 3 5 . 4}$ & 5882.9 \\
\hline
\end{tabular}

TABLE III: PROPOSED FUTURE RWH TANK SiZE (LITRES) IN LANCASHIRE (BOLD INDICATES AN INCREASE IN TANK SIZE)

\begin{tabular}{|l|l|c|l|l|l|l|}
\hline $\begin{array}{l}\text { Time } \\
\text { period }\end{array}$ & \multicolumn{2}{|c|}{ Property 1 } & \multicolumn{2}{|c|}{ Property 2 } & \multicolumn{2}{|l|}{ Property 3 } \\
\hline & A1FI & B1 & A1FI & B1 & A1FI & B1 \\
\hline $\begin{array}{l}\text { Base } \\
\text { period }\end{array}$ & 1554.4 & 1554.4 & 2590.6 & 2590.6 & 3885.91 & 3885.9 \\
\hline $2020 \mathrm{~s}$ & $\mathbf{1 5 5 4 . 6}$ & 1539.6 & $\mathbf{2 5 9 1 . 0}$ & 2566.0 & $\mathbf{3 8 8 6 . 5 3}$ & 3849.1 \\
\hline $2050 \mathrm{~s}$ & $\mathbf{1 5 9 3 . 0}$ & 1506.1 & $\mathbf{2 6 5 5 . 0}$ & 2510.1 & $\mathbf{3 9 8 2 . 5 6}$ & 3765.2 \\
\hline $2080 \mathrm{~s}$ & $\mathbf{1 5 9 3 . 0}$ & 1507.3 & $\mathbf{2 6 5 5 . 0}$ & 2512.1 & $\mathbf{3 9 8 2 . 5 6}$ & 3768.2 \\
\hline
\end{tabular}

TABLE IV: PROPOSED FutURE RWH TANK SIZE (LITRES) IN CHESHIRE (BOLD INDICATES AN INCREASE IN TANK SIZE)

\begin{tabular}{|l|l|l|l|l|l|l|}
\hline \multicolumn{1}{|c|}{$\begin{array}{l}\text { Time } \\
\text { period }\end{array}$} & \multicolumn{2}{|c|}{ Property 1 } & \multicolumn{2}{|c|}{ Property 2 } & \multicolumn{2}{l|}{ Property 3} \\
\hline & A1FI & B1 & A1FI & B1 & A1FI & B1 \\
\hline $\begin{array}{l}\text { Base } \\
\text { period }\end{array}$ & 1054.5 & 1054.5 & 1757.5 & 1757.5 & 2636.3 & 2636.3 \\
\hline 2020 s & $\mathbf{1 0 8 9 . 3}$ & 1036.6 & $\mathbf{1 8 1 5 . 6}$ & 1727.7 & $\mathbf{2 7 2 3 . 3}$ & 2591.5 \\
\hline 2050 s & $\mathbf{1 1 4 8 . 6}$ & $\mathbf{1 0 6 3 . 0}$ & $\mathbf{1 9 1 4 . 3}$ & $\mathbf{1 7 7 1 . 6}$ & $\mathbf{2 8 7 1 . 5}$ & $\mathbf{2 6 5 7 . 5}$ \\
\hline 2080 s & $\mathbf{1 1 4 8 . 6}$ & 1019.8 & $\mathbf{1 9 1 4 . 3}$ & 1699.6 & $\mathbf{2 8 7 1 . 5}$ & 2549.4 \\
\hline
\end{tabular}

\section{CONCLUSION}

Using rainwater in buildings reduces demand for potable water and reduces storm water problems in overloaded sewers, both are urgent requirements as a sustainable technology to create smart building.

The design of rwh systems for three properties at three selected sites in of north west of england has been evaluated using simple approach (based on british standard bs 8515).the three systems for the properties use the same parameter values and future rainfall for the sites with change only in roof area and occupants. The effect of projected future rainfall show that design and saving efficiency of the system are affected with the climate change especially under the high scenario of the ipcc. This would necessitate to the engineer to consider the climate change when design the rwh system.

\section{ACKNOWLEDGMENT}

This study is conducted as part of a research programme at
Low Carbon Innovation Hub, Liverpool John Moores University. The authors, in particular, would like to acknowledge the financial support rendered by European Regional Development Fund 2007-2013 (ERDF, X03166PR). Special thanks are due United Utility and MWH Ltd for obtaining rainfall data.

\section{REFERENCES}

[1] C. Hassell. Rainwater Harvesting in the UK- A solution to increasing water shortages. [Online]. Available: www.ech2o.co.uk/downloads/delhiabstract.pdf

[2] Environmental Assessment Method. [Online]. Available: http://www.breeam.org/.

[3] Draft Strategy for Sustainable Construction: A consultation paper. Department for Business, Enterprise and Regulatory Reform. [Online]. Available: http://www.berr.gov.uk/files/file40641.pdf.

[4] DEFRA. Future Water: The Government's Water Strategy for England. February. [Online]. Available: http://www.defra.gov.uk/environment/water/strategy/pdf/future-water. pdf.

[5] OFWAT. Strategic Direction Statements. OFWAT. [Online]. Available: http://www.ofwat.gov.uk/aptrix/ofwat/publish.nsf/Content/navigation -pr09sds.

[6] DEFRA. Draft Flood and Water Management Bill. DEFR. [Online]. Available:

http://www.defra.gov.uk/corporate/consult/flood-water-bill/index.htm

[7] S. Ward, F. A. Memon, and D. Butler, "Rainwater harvesting: model-based design evaluation," Water Science \& Technology, vol. 6, no.1, pp. 85-96, 2010.

[8] R. M. Roebuck and R. M. Ashley, "Predicting the hydraulic and life-cycle cost performance of rainwater harvesting systems using a computer based modelling tool," in Proc. the 7th International Conference on Urban Drainage and 4th International Conference on Water Sensitive Urban Design, Melbourne, Australia, 2-7 April, 2006, vol. 2, pp. 2699-2706.

[9] Y. Kim and M. Han, "A Rainfall-storage-runoff (RSR) model for the design of a rainwater tank effective for flow control in urban drainage pipes," in Proc. the 2nd IWA International Rainwater Harvesting Workshop, Beijing, China, 11 September 2006.

[10] A. Fewkes and P. Warm, "A method of modelling the performance of rainwater collection systems in the UK," Serv. Eng. Res. Technol, vol. 2, pp. 257-265, 2000.

[11] Met office. North West England and Isle of Man. [Online]. Available: http://www.metoffice.gov.uk/climate/uk/nw.

[12] M. Abdellatif, W. Atherton, and R. Alkhaddar, "Hybrid generalized linear and lavender-marquardt artificial neural network approach for downscaling future rainfall in North Western England," Hydrology Research J., vol. 44, no. 6, pp. 1084-1101, 2013.

[13] G. Jenkins, M. Perry, and G. Prior, The Climate of the United Kingdom and recent Trends, Met Office Hadley Centre, Revised edition, ISBN 978-1-906360-05-4, 2009.

[14] A. J. Dobson, An Introduction to Generalized Linear Models. London, Chapman \& Hall / CRC, 2002.

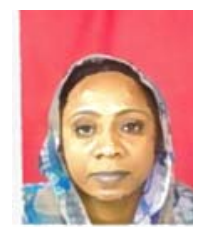

M. Abdellatif was born in Sudan in 1974. She received her $\mathrm{PhD}$ in civil engineering from Liverpool John Moores University (LJMU) UK in 2013.

She is currently working as a researcher at the Low Carbon Innovation $\mathrm{Hub}$ at LJMU and worked previously as Lecturer. She involved herself in many research projects at Unesco and is a chair of water resource in Sudan. She has a number of publications, the recent ones are: M. Abdellatif, Causes, Impacts, and Solutions to Global Warming, New York, US, Springer, 2013, ch. 12. M. Abdellatif, "A hybrid generalised linear and Levenberg-Marquardt ANN approach for downscaling future rainfall," Hydrology Research Journal, vol. 44, no. 6, pp. 1084-1101, 2013.

Her current research areas of interests are urban drainage systems modelling, climate change impact modelling, environmental modelling, surface water hydrology and rainfall extremes analysis.

Dr. Abdellatif has a number of awards: Full scholarship to attend the Impact World 2013 Workshop, Potsdam Institute, Potsdam, Germany, May 2013. Best paper award at the GCGW conference, July, 2012, ITU, Istanbul, Turkey. Best paper award at 7th Annual Bean Conference, May, 2012, LJMU, Liverpool, UK. Studentship from the School of Built 
Environment, Liverpool John Moores University, UK, 2010, to study $\mathrm{PhD}$. IHE scholarship to study PhD, 2000, HRI/IHE, Egypt.

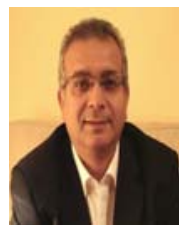

A. Al-Shamma'a was born in Iraq in 1964 . He received his $\mathrm{MSc}$ and $\mathrm{PhD}$ degrees from the University of Liverpool, UK in 1990 and 1993 respectively in the electrical engineering and electronics. He is currently the dean of Faculty of Technology Environment at Liverpool John Moores University.

His extensive research area covers a wide range of applied industrial science including advance technologies for renewable energies from waste including biodiesel, bioethanol and biobutanol, waste recycling, environmental and sustainable agendas, wireless sensors for different applications, He has published over 300 per reviewed scientific publications, 15 patents, 6 book chapters and a book editor.

Prof. Al-Shamma'a is an associate member of IEEE, senior fellow member of IET (previously IEE), fellow member of Institute of Physics, senior member of the International Plasma Chemistry Society, board member of the International Microwave Power Institute, and member of the American Society for Engineering Education. He has a number of awards: Liverpool City Council Teacher of the Year in 1998 and 1999, the University of Liverpool, Sir Alastair Pilkington award, in the category of Sustained Excellence in Teaching in September 2000, Best UK Researcher in UK research Excellence, House of Commons in 2001.

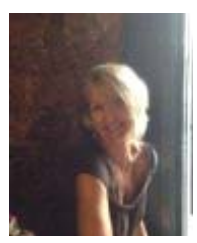

S. Tunnington has 30 years experience in running and managing a landscape construction company leading to the uptake of rain water harvesting which is when RainCatcher was born, 8 years on. Suzanne is one of the leading specialists in UK running certified and non-certified training within the rain harvesting sector and designing bespoke rain harvesting and grey water systems both for industry and the consumer. Rain Catcher products and services currently manufacture water tanks and filters and has a sole distributor agreement with a long standing German manufacturer of tanks and systems. This coupled with valuable assistance from Liverpool John Moores University and the Government backed Growth Accelerator program is set to help Suzanne take the company to the next level.

She is currently the manager of Rain Catcher Products and Services. Mrs. Tunnington is a member of Liverpool Chamber of Commerce, Chester Network, Construction \& amp; Building Materials- Professionals Group, Ecogrid, Green and SuDS.

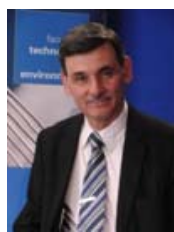

R. Alkhaddar was born in Iraq in 1956. He has a $\mathrm{PhD}$ in civil engineering from University of Strathclyde, Glasgow, UK in 1988.

$\mathrm{He}$ is currently a professor of water and Environmental engineering and the head of the Liverpool Centre for Environmental Technologies (LCET) at Liverpool John Moores University. He has extensive experience in wastewater treatment methods. Rafid has published over 120 articles in refereed journals and international conferences; he is on the editorial board and a reviewer for a number of international journals. He has managed to attract over $£ 1.2$ Million in research and consultancy funding since the year 2000 . He has very strong links with the Water and Env. industry. He has excellent links with professional bodies especially the Chartered Institution of Water and Environmental Management (CIWEM) where he is a fellow and on its Board of Trustees. He is currently the president elect for the Institution and will serve his term of office in 2015-16. He is a council member on the Canals and Rivers Trust.

Prof. Alkhaddar is a fellow of The Chartered Institution of Water and Environmental Management UK (FCIWEM), a registered Chartered Engineer with the Engineering Council UK (CEng), a Chartered Environmentalist (CEnv), a Chartered Water and Environmental Manager and a European Engineer (EurIng).

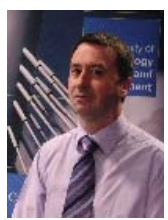

W. Atherton has a $\mathrm{PhD}$ in civil engineering from Liverpool John Moores University (LJMU), UK obtained in 2008. His background was originally in mechanical Engineering; however he decided to focus on civil engineering as a part of his staff development. After obtaining a first class honors degree in civil engineering he took up a part-time teaching position before his successful appointment as a full-time senior lecturer within the School of the Built Environment. In 2005, a work was completed on a project funded by the Health and Safety Executive (HSE), conducting research into the catastrophic failure of primary storage tanks, secondary containment and overtopping with associated dynamic pressures. His interest has recently developed in the physical modelling for the impact of waves on structures allowing the determination of dynamic pressures and global forces. He has presented research papers at national and international conferences and has a number of journal publications.

Dr. Atherton has been nominated for teaching awards on a number of occasions and is currently a programme leader in the School of the Built Environment. 